\title{
Dipeptidyl-Peptidase IV Inhibitors and glycemic control in type 2 Diabetes Mellitus
}

\author{
Lokendra Bahadur Sapkota, ${ }^{1}$ Sangita Thapa ${ }^{2}$ \\ ${ }^{1}$ Department of Biochemistry, ${ }^{2}$ Department of Microbiology, Chitwan Medical College, Bharatpur, Nepal
}

\section{Correspondence \\ Dr Lokendra B Sapkota, \\ Department of Biochemistry, \\ Chitwan Medical College, \\ Bharatpur, Nepal \\ Email: sdrloken@gmail.com}

DOI: http://

dx.doi.org/10.3126/

jcmsn.v12i1.14683

\begin{abstract}
Background \& Objectives: Type 2 diabetes mellitus (T2DM) is a progressive disease, characterized by insulin resistance, impaired glucoseinduced insulin secretion, inappropriately elevated glucagon concentrations, and hyperglycemia. Many patients cannot obtain satisfactory glycemic control with current therapies. New and more effective agents, targeted not only at treatment, but also at prevention of the disease, its progression, and its associated complications, are, therefore, required. The dipeptidyl peptidase-4 (DPP-4) inhibitors are a newer class of oral drugs for the treatment of T2DM. They inhibit the breakdown of glucagon-like peptide-1 (GLP-1) and glucose-dependent insulinotropic polypeptide (GIP) thereby increasing the incretin effect in patients with T2DM. In clinical practice they are associated with significant reductions in $\mathrm{HbA1c}$, no weight gain and a low risk of hypoglycemia. Since incretin response is markedly diminished in Asian populations, these agents can be used to achieve satisfactory glycemic control in Nepalese T2DM patients Key words: DPP-4 inhibitors; incretin hormones; type 2 DM
\end{abstract}

Citation: Sapkota LB, Thapa S. Dipeptidyl-Peptidase IV Inhibitors and glycemic control in type 2 Diabetes Mellitus. JCMS Nepal. 2016;12(1):28-32.

\section{INTRODUCTION}

The prevalence of type $2 \mathrm{DM}$ is increasing at an alarming rate both in the developed and developing countries of the world. ${ }^{1}$ It is characterized by insulin resistance and impaired $\beta$-cell secretory function. ${ }^{2}$ Many studies have already proven that people with type $2 \mathrm{DM}$ have reduced $\beta$-cell function $(\sim 50 \%)$ at the time of diagnosis which continues to decline regardless of treatment. ${ }^{3}$ This shows that the defect occurs early and is important in the pathogenesis of the disease, rather than simply arising as a consequence of hyperglycemia. Many patients cannot obtain satisfactory glycemic control with current therapies, and eventually develop microvascular and macrovascular diabetic complications. ${ }^{4}$ To prevent such complications, new and more effective pharmacological agents are required which not only targets treatment of type 2 DM, but also its prevention, progression, and associated complications. One new approach which is rapidly undergoing trials worldwide with promising results is the use of agents that are based on gut incretin hormones glucagon like peptide-1 (GLP-1) and glucose dependent insulinotropic peptide (GIP). These two hormones are secreted by intestinal mucosal cells as a result of food ingestion and regulate the endocrine secretion of pancreas; hence the name incretins. ${ }^{5}$ These incretins undergo degradation by the action of enzyme Dipeptidyl peptidase-IV, which are ubiquitously distributed in a number of sites, including the endothelial cells of small gut arterioles. ${ }^{6}$ As a result, the majority of GLP-1 and GIP is inactivated before reaching the systemic circulation.

\section{Biology of DPP-4}

DPP-4 is a 766-amino acid serine protease that preferentially cleaves peptide hormones containing a position two alanine or proline. The human gene encoding DPP-4 has been localized to chromosome 2 locus $2 \mathrm{q} 24 .{ }^{3.7}$ Majority of the DPP-4 protein is extracellular, with a hydrophobic transmembrane sequence anchoring the protein in the cell membrane. ${ }^{8}$ It is a single-pass type II integral transmembrane glycoprotein with its carboxyterminus outside the membrane and a short Nterminal cytoplasmic extension. It was originally identified as a protein on lymphocytes. DPP-4 is widely expressed in several cell types, particularly in exocrine glands and absorptive epithelia. In humans, DPP-4 found in the brush borders of epithelial cells of the proximal convoluted tubules in the kidney and of the small and large intestine as well as in prostate, liver hepatocytes, and activated leukocytes (T-, B- and natural killer cells). ${ }^{9}$

DPP-4 is also known as adenosine deaminase binding protein (ADBP) or T-cell activation antigen CD26. ${ }^{10}$ It catalyses the release of an N-terminal dipeptide provided that the next to last residue is proline, hydroxyproline, dehydroproline or alanine. ${ }^{11}$ Only oligopeptides in the trans conformation are able to bind to the active site of DPP-4. Several peptides have been identified 
as DPP4 substrates. These substrates include neuropeptides, chemokines, and the incretin hormones. ${ }^{12}$ Both GLP-1 and GIP are inactivated by DPP-4 resulting in a short half-life, which is 1 to 2 min for GLP-1 and 5 to 7 min for GIP. ${ }^{13}$ Almost $50 \%$ of this degradation occurs at the intestinal capillaries close to the site of GLP-1 and GIP release.

\section{Physiology of DPP-4 Inhibitors}

DPP-4 inhibitors are a newer class of oral hypoglycemic agents (OHA's) that regulates blood glucose level by inhibiting the action of DPP-4.

Meal ingestion with increased glucose concentration in blood stimulates release of the endogenous incretins GLP-1 and GIP which in turn stimulates insulin release and inhibit glucagon release resulting in lower blood glucose. ${ }^{14}$ They are rapidly inactivated by DPP-4. Therefore DPP-4 inhibitors prolong the action of endogenous incretins, enhancing the first-phase insulin response. ${ }^{15,16}$

DPP-4 inhibitors were first introduced in 2006 for the management of hyperglycemia in type $2 \mathrm{DM}$. Currently, sitagliptin, vildagliptin, saxagliptin, linagliptin and alogliptin have been approved by the US Food and Drug Administration (FDA) and the European Medicines Agency for use in patients with type 2 diabetes.

DPP-4 inhibitors only enhance the body's own ability to release insulin and regulate blood glucose, hence these drugs are applicable only in the management of type $2 \mathrm{DM}^{17}$ Their effect is dependent on some function of the insulin-releasing beta cells in the pancreas, and people with type 1 diabetes generally do not have a significant number of functioning pancreatic beta cells.

Examples of DPP-4 inhibitors which are commonly used worldwide.

- Sitagliptin (First discovered and FDA approved 2006, marketed by Merck \& Co. as Januvia), ${ }^{18}$

- Vildagliptin (EU approved 2007, marketed in the EU by Novartis as Galvus), ${ }^{19}$

- Saxagliptin (FDA approved in 2009, marketed as Onglyza),

- Linagliptin (FDA approved in 2011, marketed as Tradjenta by Eli Lilly Co and Boehringer Ingelheim), ${ }^{20}$

- Anagliptin (approved in Japan in 2012, marketed by Sanwa Kagaku Kenkyusho Co., Ltd. and Kowa Company, Ltd.) ${ }^{21}$

- Teneligliptin (approved in Japan in 2012) ${ }^{22}$

- Alogliptin (FDA approved 2013, marketed by Takeda Pharmaceutical Company)

- Gemigliptin (being developed by LG Life Sciences) ${ }^{23}$

- Dutogliptin (being developed by Phenomix Corporation), Phase III ${ }^{24}$

DPP-4 inhibitors and type 2 DM
The combined incretin response (GLP-1 and GIP) accounts for $50-70 \%$ of total postprandial insulin production. ${ }^{25} \quad$ Both insulin secretion and biosynthesis are enhanced, while over-secretion of glucagon is suppressed, restoring the normal glucagon: insulin relationship, which is important for the regulation of hepatic glucose metabolism. ${ }^{26}$ Though $\beta$-cell trophic effects have been demonstrated in animal and in vitro studies, clinical studies have shown that $\beta$ - cell function improves. ${ }^{27}$ In patients with type $2 \mathrm{DM}$ the incretin response is markedly diminished. Circulating levels of DPP-4 activity have been reported to be higher in some studies of subjects with chronic hyperglycemia and type $2 \mathrm{DM} .^{28,29}$ So, there exist a clear relationship between type 2 DM, incretin response and DPP-4 inhibitors. This newer group of drugs help in prolonging the incretin effects by inhibiting the action of DPP-4. By DPP-4 inhibition, high concentration of endogenously produced GLP-1 and GIP is available in the circulation. As a result, there is enhancement in insulin secretion, suppression of glucagon secretion and improvement in beta-cell function.

\section{Clinical trials, safety and efficacy of DPP-4 inhibitors}

Numerous studies have been carried out so far to evaluate the effects of DPP-4 inhibitors in people with type 2 DM. Clinical trials have demonstrated that sitagliptin is safe and efficacious for the management of hyperglycemia in type 2 diabetes. Sitagliptin administered in a dose of 100-mg to 200 -mg daily reduced hemoglobin A1c (HbA1c) levels ranging from 0.7 to $1.0 \%$, within a duration of 24 weeks. These differences were statistically significant when compared to placebo $(\mathrm{P}<0.001){ }^{30}$ Improvements in fasting plasma glucose and postprandial glucose levels were also reported in those treated with sitagliptin. In one trial, 701 patients with a mean baseline $\mathrm{HbA} 1 \mathrm{c}$ of $8 \%$ (range: $7-10 \%)$ who were previously treated with metformin continued therapy with metformin and were randomized to receive either $100 \mathrm{mg}$ sitagliptin or placebo daily for 24 weeks. ${ }^{31}$ Patients in the placebo group experienced no changes in $\mathrm{HbA1c}$, whereas those treated with sitagliptin plus metformin realized a $0.65 \%$ reduction in $\mathrm{HbAlc}$ at 24 weeks. Similar results have been published from other clinical trials evaluating the efficacy of combination metformin and sitagliptin therapy. ${ }^{32,33}$ Significant reduction in HbAlc have been achieved with concomitant use of DPP-4 inhibitors with pioglitazone. ${ }^{34}$

Kim et al. in their review of DPP-4 inhibitors provided evidence that this class of agents may be more effective in Asian patients. ${ }^{35}$ The findings of Seino et al. suggest a better response of Asian patients to DPP-4 inhibitors, raising the possibility that patients of Asian ethnicity have relatively more 
defects in meal associated insulin secretion.

Unlike traditional treatments which do not seem to address the progressive decline in $\beta$-cell function, DPP-4 inhibitors could theoretically preserve and even reverse the progressive loss of insulin secretory capacity, although long-term studies in type 2 diabetic patients will be required to demonstrate this change.

DPP-4 inhibitors augment insulin secretion in a glucose-dependent manner, thus preventing hypoglycemia when used as monotherapy or in combination with other OHA's agents. ${ }^{33}$ They are not associated with increased risk for diarrhea, nausea or vomiting. ${ }^{32,38,39}$ Compared with other antidiabetic agents, gastrointestinal adverse events were more common in patients receiving metformin or a GLP-1 agonist than a DPP-4 inhibitor. ${ }^{40}$ Preclinical data have indicated a potential cardioprotective effect of DPP-4 inhibitors by increasing the concentration not only of GLP-1, but of other vasoactive peptides as well. ${ }^{41}$ Renal excretion is the main elimination pathway for most DPP-4 inhibitors. It is therefore necessary to adjust their dose in patients with moderate or severe renal impairment. Sitagliptin has not been found to be nephrotoxic in clinical trials and was well tolerated at adjusted doses in patients with moderate or severe renal insufficiency, including those with end -stage renal disease treated with dialysis. ${ }^{42,43}$

Clinically approved DPP -4 inhibitors are generally well tolerated in T2DM patients. As a drug class, the DPP-4 inhibitors have become accepted in clinical practice due to their excellent tolerability profile, with a low risk of hypoglycemia, a neutral effect on body weight, and once-daily dosing. The National Institute for Health and Clinical Excellence (NICE) clinical guideline for T2DM issued in 2009 in the United Kingdom suggests adding a DPP-4 inhibitor instead of a sulfonylurea as a second-line treatment to first line metformin if there is a considerable risk for hypoglycemia or if a sulfonylurea is contraindicated or not tolerated. ${ }^{44}$

\section{CONCLUSION}

The DPP-4 inhibitors represent a highly promising, novel class of oral agents for the treatment of T2DM. Their novelty lies in their dual action on $\alpha-$ and $\beta-$ cell function, leading to an improved profile of glucagon and insulin secretion patterns after meal. These drugs are weight-neutral, do not cause hypoglycemia, and are not associated with severe gastrointestinal adverse events. They seem likely to be as efficacious as currently available oral antidiabetic agents, giving sustainable and clinically meaningful reductions in $\mathrm{HbAlc}$ levels, both as monotherapy and in combination with other antidiabetic agents, and apparently can be used across a broad spectrum of patient groups (elderly; obese, poorly controlled diabetes; hepatic or renal failure). As a class, DPP-4 inhibitors appear to have an excellent safety profile, with little or no risk for hypoglycemia, no weight gain, and the potential benefit of addressing the islet dysfunction that characterizes type $2 \mathrm{DM}$. Since incretin response is more diminished in Asian populations this group of drugs can address the therapeutic needs of Nepalese type 2 diabetic population and can be effectively used as a monotherapy or combination therapy in the glycemic control. .

\section{REFERENCES}

1. Feinglos MN, Bethel MA. Type 2 diabetes mellitus: an evidence-based approach to practical management. Totowa, NJ: Humana Press 2008;8:17-33.

2. The Expert Committee on the Diagnosis and Classification of Diabetes Mellitus: Follow-up report on the diagnosis of diabetes mellitus. Diabetes Care. 2003;26:3160-7. DOI: 10.2337/diacare.26.11.3160.

3. Fonseca VA. Defining and Characterizing the Progression of Type 2 Diabetes. Diabetes Care. 2009;32(2):S151S156. DOI: 10.2337/dc09-S301. PMID:19875543.

4. American Diabetes Association Standards of medical care in diabetes. Diabetes Care. 2013; 36(1): S11-S66. PMID:23264422.

5. Wook K and Josephine ME. The Role of Incretins in Glucose Homeostasis and Diabetes Treatment. Pharmacol Rev. 2008;60(4):470-512. DOI: 10.1124/pr.108.000604. PMID: 19074620 .

6. Deacon CF. Circulation and degradation of GIP and GLP1. Horm Metab Res. 2004; 36 (11-12): 761-5. DOI: 10.1055/s-2004-826160. PMID:15655705.

7. Abbott CA, Baker E, Sutherland GR, Mc-Caughan GW: Genomic organization, exact localization, and tissue expression of the human CD26 (dipeptidyl peptidase IV) gene. Immunogenetics. 1994;40:331-8. DOI: 10.1007/ BF01246674. PMID:7927537.

8. Durinx C, Lambeir AM, Bosmans E, Falmagne JB, Berghmans R, Haemers A, Scharpe S, De Meester I: Molecular characterization of dipeptidyl peptidase activity in serum: soluble CD26/dipeptidyl peptidase IV is responsible for the release of X-Pro dipeptides. Eur $\mathrm{J}$ Biochem. 2000;267:5608-13. DOI: 10.1046/j.14321327.2000.01634.x.

9. Lojda Z. Studies on dipeptidyl(amino)peptidase IV (glycyl-proline naphthyl-amidase).II Blood vessels. Histochemistry. 1979; 59: 153-66. DOI: 10.1007/ BF00495663. PMID:429202.

10. Kameoka J, Tanaka T, Nojima Y, Schlossman SF, Morimoto C. Direct association of adenosine deaminase with a $\mathrm{T}$ cell activation antigen, CD26. Science. 1993;261:466-9. DOI: $\quad 10.1126 /$ science.8101391. PMID:8101391

11. Cunningham DF, O'Connor B. Proline specific peptidases. Biochim Biophys Acta. 1997;1343:160-86. DOI: 10.1016/S0167-4838(97)00134-9.

12. Lambeir AM, Durinx C, Proost P, Damme JV, Scharpe S, Meester DI. Kinetic study of the processing by dipeptidylpeptidase IV/CD26 of neuropeptides involved in pancreatic insulin secretion. FEBS Lett. 2001;507:32730. DOI: 10.1016/S0014-5793(01)02982-9.

13. Amori RE, Lau J, Pittas AG. Efficacy and safety of incretin therapy in type 2 diabetes: systematic review and meta-analysis. JAMA. 2007;298(2):194-206. DOI: 10.1001/jama.298.2.194. PMID:17622601

14. Mest HJ, Mentlein R. Dipeptidyl peptidase inhibitors as a 
new drugs for the treatment of type 2 diabetes. Diabetolgia. 2005; 48(4): 616-620. DOI: $10.1007 / \mathrm{s} 00125$ -005-1707-5. PMID:15770466.

15. Mohan V, Yang WY, Son HY, Xu L, Noble L, et al. Efficacy and safety of sitagliptin in the treatment of patients with type 2 diabetes in China, India, and Korea. Diabetes Res Clin Pract. 2009; 83(1): 106-116. DOI: 10.1016/j.diabres.2008.10.009. PMID:19097665.

16. Green BD, Flatt PR, Bailey CJ. Dipeptidyl peptidase IV (DPP IV) inhibitors: a newly emerging drug class for the treatment of type 2 diabetes. Diabetes Vasc Dis Res. 2006; 3: $159-65$. DOI: 10.3132/dvdr.2006.024. PMID:17160910.

17. Marino MT. DPP-4 Inhibitors. Diabetes selfmanagement 2009 Aug 11.

18. FDA Approves New Treatment for Diabetes. U.S. Food and Drug Administration (FDA). October 17, 2006.

19. EU approves Novartis's Eucreas diabetes drug. Reuters, February 25, 2008.

20. FDA Approves Type 2 Diabetes Drug from Boehringer Ingelheim and Lilly. Gen News Highlights May 3, 2011.

21. Graul AI, Lupone B, Cruces E, Stringer M. 2012 in Review - Part I: The Year's New Drugs and Biologics. Drugs of Today. 2013; 49(1):33-68. DOI:10.1358/ dot.2013.49.1.1933991

22. Bronson J, Black A, Murali Dhar TG, Ellsworth BA, Merritt JR. Teneligliptin (Antidiabetic)". Annual Reports in Medicinal Chemistry. 2011; 48: 523-524. doi:10.1016/b978-0-12-417150-3.00028-4. DOI:10.1016/ B978-0-12-417150-3.00028-4

23. Kim SH, Lee SH, Yim HJ. Gemigliptin, a novel dipeptidyl peptidase 4 inhibitor: first new anti-diabetic drug in the history of Korean pharmaceutical industry. Arch Pharm Res. 2013;36(10): 1185-8. DOI:10.1007/ s12272-013-0171-x.

24. Forest Splits With Phenomix. San Diego Business Journal, Tuesday, April 20, 2010 http://www.sdbj.com/ news/2010/apr/20/forest-splits-phenomix

25. Nauck MA, Homberger E, Siegel EG, Allen RC, Eaton RP, Ebert R, Creutzfeldt W. Incretin effects of increasing glucose loads in man calculated from venous insulin and C-peptide responses. J Clin Endocrinol Metab. 1986; 63: 492-498. DOI: 10.1210/jcem-63-2-492. PMID:3522621.

26. Deacon CF, Holst JJ. Dipeptidyl peptidase IV inhibitors: a promising new therapeutic approach for the management of type 2 diabetes. Int J Biochem Cell Biol. 2006; 38: 831-44.

DOI: 10.1016/j.biocel.2005.09.011. PMID:16242377.

27. Pospisilik JA, Stafford SG, Demuth HU, McIntosh CH, Pederson RA. Long-term treatment with dipeptidyl peptidase IV inhibitor improves hepatic and peripheral insulin sensitivity in the VDH Zucker rat: a euglycemichyperinsulinemic clamp study. Diabetes. 2003;51:267783.

DOI: $10.2337 /$ diabetes.51.9.2677.

28. Mannucci E, Pala L, Ciani S, Bardini G, Pezzatini A, Sposato I, Cremasco F, Ognibene A, Rotella CM. Hyperglycaemia increases dipeptidyl peptidase IV activity in diabetes mellitus. Diabetologia. 2005; 48: 1168-72. DOI: $10.1007 / \mathrm{s} 00125-005-1749-8$. PMID:15864535.

29. Ryskjaer J, Deacon CF, Carr RD, Krarup T, Madsbad S, Holst J, Vilsboll T. Plasma dipeptidyl peptidase-IV activity in patients with type-2 diabetes mellitus correlates positively with HbAlc levels, but is not acutely affected by food intake. Eur J Endocrinol 2006; 155: 485 -493. DOI: 10.1530/eje.1.02221. PMID:16914604.
30. Aschner P, Kipnes M, Lunceford M, Sanchez M, Mickel C, Williams-Herman DE. Effect of the dipeptidyl peptidase-4 inhibitor sitagliptin as monotherapy on glycemic control in patients with type 2 diabetes. Diabetes Care. 2006;29:2632-37. DOI: 10.2337/dc060703. PMID:17130196.

31. Charbonnel B, Karasik A, Liu J, Wu M, Meininger G. Efficacy and safety of the dipeptidyl peptidase-4 inhibitor sitagliptin added to ongoing metformin therapy in patients with type 2 diabetes inadequately controlled with metformin alone. Diabetes Care. 2006;29:2638-43. DOI: $10.2337 / \mathrm{dc} 06-0706$. PMID:17130197.

32. Williams-Herman D, Goldstein BJ, Feinglos MN, Lunceford JK, Johnson J. Initial combination therapy with sitagliptin, a dipeptidyl peptidase- 4 inhibitor, and metformin provides substantial glycemic improvements and HgbAlc goal attainment in patients with type 2 diabetes mellitus (T2DM). Diabet Med. 2006;23(4):319.

33. Nauck M, Meininger G, Sheng D, Terranella L, Stein P. Efficacy and safety of the dipeptidyl peptidase-4 inhibitor, sitagliptin, compared to the sulfonylurea, glipizide, in patients with type 2 diabetes inadequately controlled on metformin alone: a randomized, doubleblind, non-inferiority trial. Diabetes Obes Metab. 2007;9:194-205. DOI 1326.2006.00704.x. PMID:17300595.

34. Rosenstock J, Brazg R, Andryuk PJ, Lu K, Stein P. Efficacy and safety of the dipeptidyl peptidase-4 inhibitor sitagliptin added to ongoing pioglitazone therapy in patients with type 2 diabetes: a 24 week, multicenter, randomized, double-blind, placebocontrolled, parallel-group study. Clin Ther. 2006;28:1556 -68. DOI: $\quad 10.1016 /$ j.clinthera.2006.10.007. PMID:17157112.

35. Kim YG, Hahn S, Oh TJ, Kwak SH, Park KS, Cho YM. Differences in the glucose-lowering efficacy of dipeptidyl peptidase-4 inhibitors between Asians and non -Asians: a systematic review and meta-analysis. Diabetologia. 2013;56(4):696-708. DOI: 10.1007/s00125 -012-2827-3. PMID:23344728.

36. Seino Y. Relevance of incretins in the treatment of Asian patients with type 2 diabetes. Diabetes Research and Clinical Practice. 2008;79(4):37-50. DOI: 10.1016/s0168 -8227(08)70653-3.

37. Louisa M, Takeuchi M, Takeuchi M, Nafrialdi N, Setiabudy R. Incretin-based therapies for type 2 diabetes mellitus in Asian patients: analysis of clinical trials. Medical Journal of Indonesia. 2010;19:205-12. DOI: 10.13181/mji.v19i3.406.

38. Gerrald K, Van Scoyoc E, Wines R, Runge T, Jonas D. Saxagliptin and sitagliptin in adult patients with type 2 diabetes: a systematic review and meta-analysis. Diabetes Obes Metab. 2012;14:481-92. DOI: 10.1111/ j.1463-1326.2011.01540.x. PMID:22098472.

39. Goossen K, Graber S. Longer term safety of dipeptidyl peptidase- 4 inhibitors in patients with type 2 diabetes mellitus: systematic review and meta-analysis. Diabetes Obes Metab. 2012;14:1061-72. DOI: 10.1111/j.14631326.2012.01610.x. PMID:22519906.

40. Karagiannis T, Paschos P, Paletas K, Matthews D, Tsapas A. Dipeptidyl peptidase-4 inhibitors for treatment of type 2 diabetes mellitus in the clinical setting: systematic review and meta-analysis. BMJ. 2012;344:1369. DOI: $\quad$ 10.1136/bmj.e1369. PMID:22411919.

41. Scheen A. Cardiovascular effects of gliptins. Nat Rev Cardiol. $2013 ; 10: 73-84$ 
10.1038/nrcardio.2012.183. PMID:23296071.

42. Chan J, Scott R, Arjona Ferreira J, Sheng D, Gonzalez E, Davies M, et al. Safety and efficacy of sitagliptin in patients with type 2 diabetes and chronic renal insufficiency. Diabetes Obes Metab 2008;10:545-55 DOI: 10.1111/j.1463-1326.2008.00914.x. PMID:18518892.

43. Arjona Ferreira J, Marre M, Barzilai N, Guo H, Golm G, Sisk C, et al. () Efficacy and safety of sitagliptin versus glipizide in patients with type 2 diabetes and moderate-to -severe chronic renal insufficiency. Diabetes Care. 2013;36:1067-73. DOI: $\quad$ 10.2337/dc12-1365. PMID:23248197. 